\title{
DENTAL AND BASICRANIAL ANATOMY OF A LATE MIDDLE EOCENE PROTOCETID CETACEAN FROM THE SOUTHEASTERN UNITED STATES
}

\author{
HULBERT, Richard C., Dept. of Geology and Geography, Georgia Southern University, \\ Statesboro, GA 30460-8149, U.S.A.
}

The partial skeleton of a new genus and species of protocetid cetacean was collected from Burke County in the Upper Coastal Plain of Georgia. Its age, based on associated calcareous nannoplankton and mollusks, is early Bartonian, ca. 39-41 Ma. It is thus approximately contemporaneous with the Egyptian Eocetus schweinfurthi and the oldest basilosaurids, and considerably younger than all other described protocetids. About 60 skeletal elements of a single individual were recovered, including the skull, left ramus, pelvis, 12 ribs, and 23 vertebrae. The specimen is informally designated the Vogtle whale, named after its locality, the Vogtle Electric Generating Plant. Its phylogenetic position was determined by parsimony analysis to be: (Pakicetus (Rodhocetus (Protocetus (Vogtle whale (Eocetus, Basilosauridae))))).

Important dental characters of the Vogtle whale include double-rooted Pl and pl, prominent cingulae, strongly wrinkled and ornamented enamel (heaviest on P2 and P3), and triple-rooted upper molars. The carinae of the upper cheek teeth (except the P1) possess small, blunt accessory cuspules; these are strongest and most numerous on the P3 and P4. These are interpreted as homologous with the larger, sharper accessory cusps characteristic of basilosaurid cheek teeth. The talonid of the lower molars bears a single, tall, laterally compressed cusp, the hypoconid; it is separated from the massive protoconid by a vertical, carnivore-like carnassial notch. The $\mathrm{p} 4$ also has a similar but smaller hypoconid. Large wear facets reveal that the lingual surfaces of the main cusps of the P4-M3 occluded with the labial surfaces of the p4-m3, forming a continuous series of carnassial-like shearing blades. The more anteriorly located teeth show only apical wear.

In contrast, the basicranial region of the Vogtle whale's skull for the most part plesiomorphically resembles that of Protocetus and other Lutetian protocetids. The bulla is attached to the basicranium at three points, including a robust, syndesmotic articulation with the paroccipital process. There is a narrow but extensive peribullar sinus isolating the promontorium from contact with the exoccipital and basioccipital, but no true pterygoid fossa, only a shallow depression formed on the alisphenoid and pterygoid. The ventral surface of the promontorium is mostly flat. The fenestra vestibuli opens laterally and is not visible in ventral view. Of ten known basicranial apomorphies distinguishing basilosaurid cetaceans from Protocetus, the Vogtle whale shares only one with the former, an enlarged stapedial fossa.

Numerous recent discoveries of early cetaceans from Pakistan, northwestern India, and Africa have greatly narrowed the morphologic gap between terrestrial mammals (i.e., mesonychids) and Protocetus, which for a long time was the oldest known whale. But no morphologic intermediaries between Protocetus and the next grade of cetacean evolution, the basilosaurids, were known except for a very limited number of specimens referred to Eocetus and Pappocetus. Analysis of the morphology of the Vogtle whale from the dual perspectives of phylogeny and functional anatomy permits a fuller understanding of the protocetid-basilosaurid transition. This is one of the critical steps in cetacean evolution, since it here that they became fully aquatic. 